Agenesia de arteria carótida interna: una variante poco común

\title{
Internal carotid artery agenesia: an unusual variant
}




\section{ICM 350}

Agenesia de arteria carótida interna: una variante poco común

Internal carotid artery agenesia: an unusual variant

Roberth Edmundo del Castillo Sierra, Edgar Vladimir Silva Shiquia, Diego Páez-Granda

Servicio de Radiodiagnóstico e Imagen. Hospital de Especialidades de las Fuerzas Armadas n. ㅇ 1. Quito, Ecuador

Recibido: 01/09/2021

Aceptado: 02/09/2021

Correspondencia: Edgar Vladimir Silva Shiquia. Servicio de Radiodiagnóstico e Imagen. Hospital de Especialidades de las Fuerzas Armadas n. ํ 1. Av. Queseras del Medio, 521 y Av. Gran Colombia, 593. Quito, Ecuador e-mail: edgar.v.silva@hotmail.com

DOI: 10.20960/angiologia.00350

Conflictos de interés: los autores declaran que no existe conflicto de interés.

\section{INTRODUCCIÓN}

Hombre de 48 años, militar en servicio activo que acude a un control de forma ambulatoria por presentar recidiva de masa subcutánea en la región occipital. No se detectan signos de focalidad neurológica. Se solicita TAC de cráneo simple y angio-RM de vasos cerebrales con 
técnica TOF-3D con el fin de definir de forma adecuada la lesión y valorar su posible relación con estructuras vasculares. En estos estudios de imagen se detectan de forma incidental los hallazgos señalados en las figuras 1 y 2 .

\section{PREGUNTA}

¿Cuál es la prevalencia de este hallazgo vascular incidental?:
a) $10 \%$.
b) $5 \%$.
c) $0,01 \%$.
d) $1 \%$.

\section{SOLUCIÓN}

Respuesta: c.

La agenesia unilateral de la arteria carótida interna $(\mathrm{ACl})$ es una anomalía del desarrollo extremadamente rara, con una incidencia aproximada del 0,01\% (1). Su diagnóstico generalmente es incidental durante la realización de una prueba radiológica puesto que los pacientes no presentan sintomatología. Esto se debe a que el flujo se compensa por medio de la arteria comunicante anterior o comunicante posterior (1,2) (Fig. 1).

En el momento de la evaluación de un paciente con ausencia de flujo en la $\mathrm{ACl}$, es imprescindible analizar la base del cráneo, puesto que la ausencia del canal carotídeo es el hallazgo que indica la ausencia congénita de esta estructura vascular (3) (Fig. 2).

\section{BIBLIOGRAFÍA}

1. Jianu DC, Bârsan C, Dan TF, Jianu SN, Motoc AGM, Creţu OM. Left internal carotid artery agenesis associated with communicating arteries anomalies. Rom J Morphol Embryol 2018;59(2):601-5. 


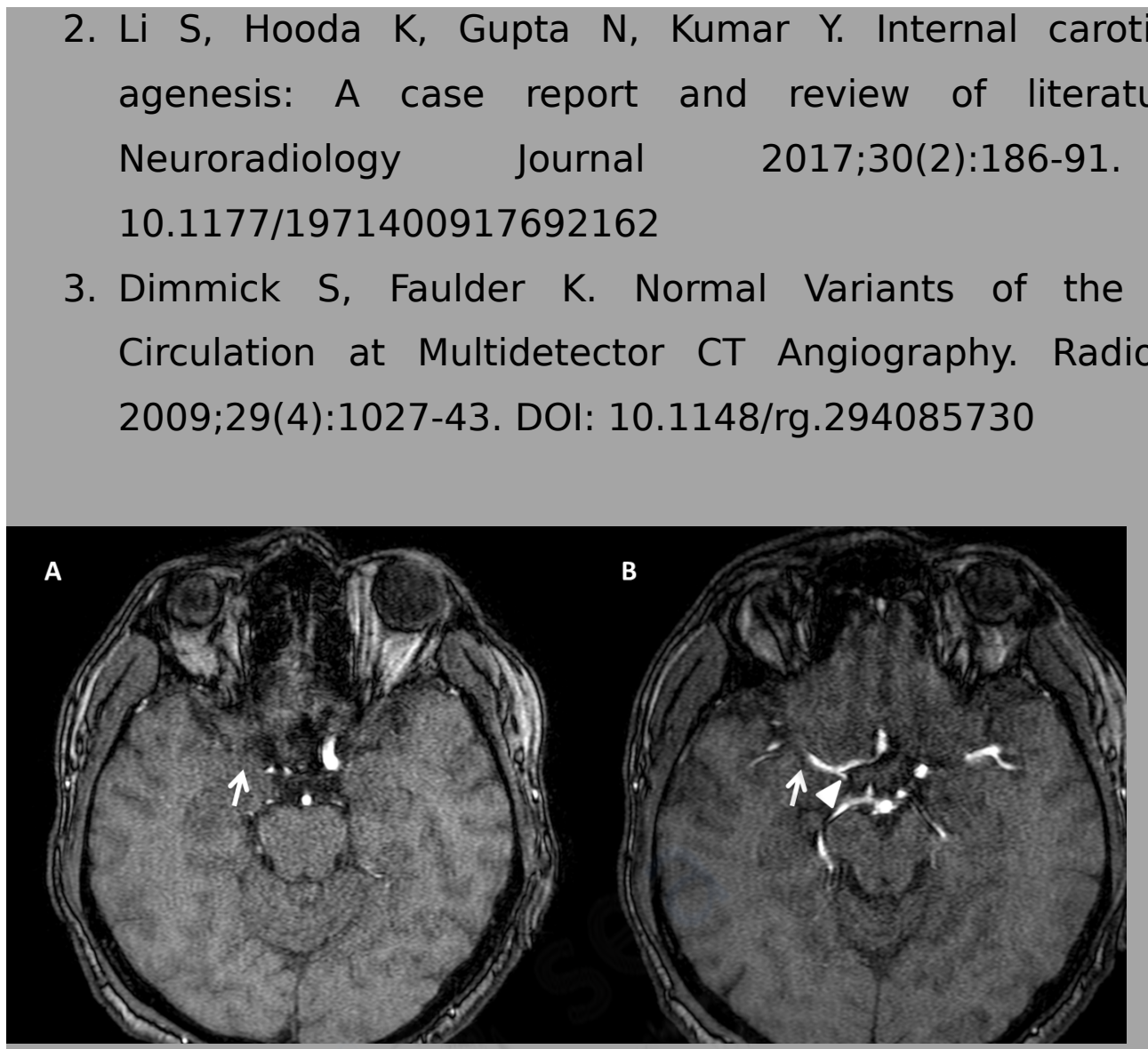

Figura 1. Angio-RM de vasos cerebrales con técnica TOF-3D. Ausencia de flujo en la arteria carótida interna derecha (la flecha en la imagen A). Se observa compensación del flujo a través de la arteria comunicante posterior homolateral (triángulo en la imagen $\mathrm{B}$ ), por lo que el segmento M1 de la arteria cerebral media derecha es permeable (flecha en la imagen B).

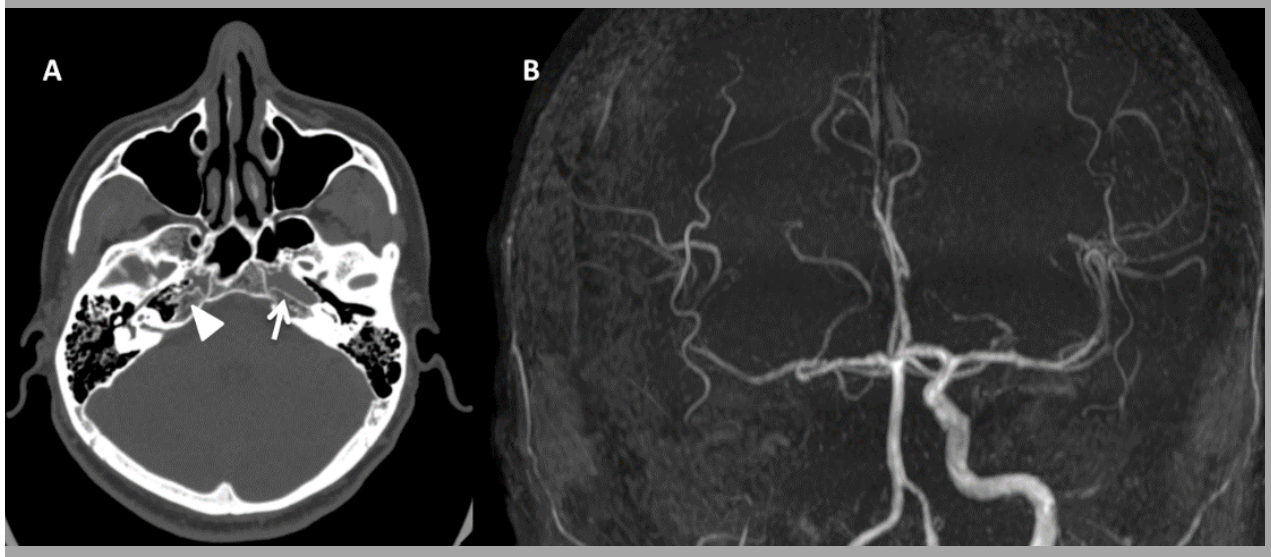

Figura 2. TAC simple de cráneo en ventana ósea (A) y reconstrucción 3D de angio-RM de vasos cerebrales con técnica TOF-3D (B). En la 
imagen A no logra identificarse el canal carotídeo derecho (triángulo). En la imagen B se corrobora la agenesia de la arteria carótida interna derecha. 